\title{
Situational Analysis of Farm Animal Cruelty in Large Farms, General Community \& in Relevant Government Authorities Operating In Kenya
}

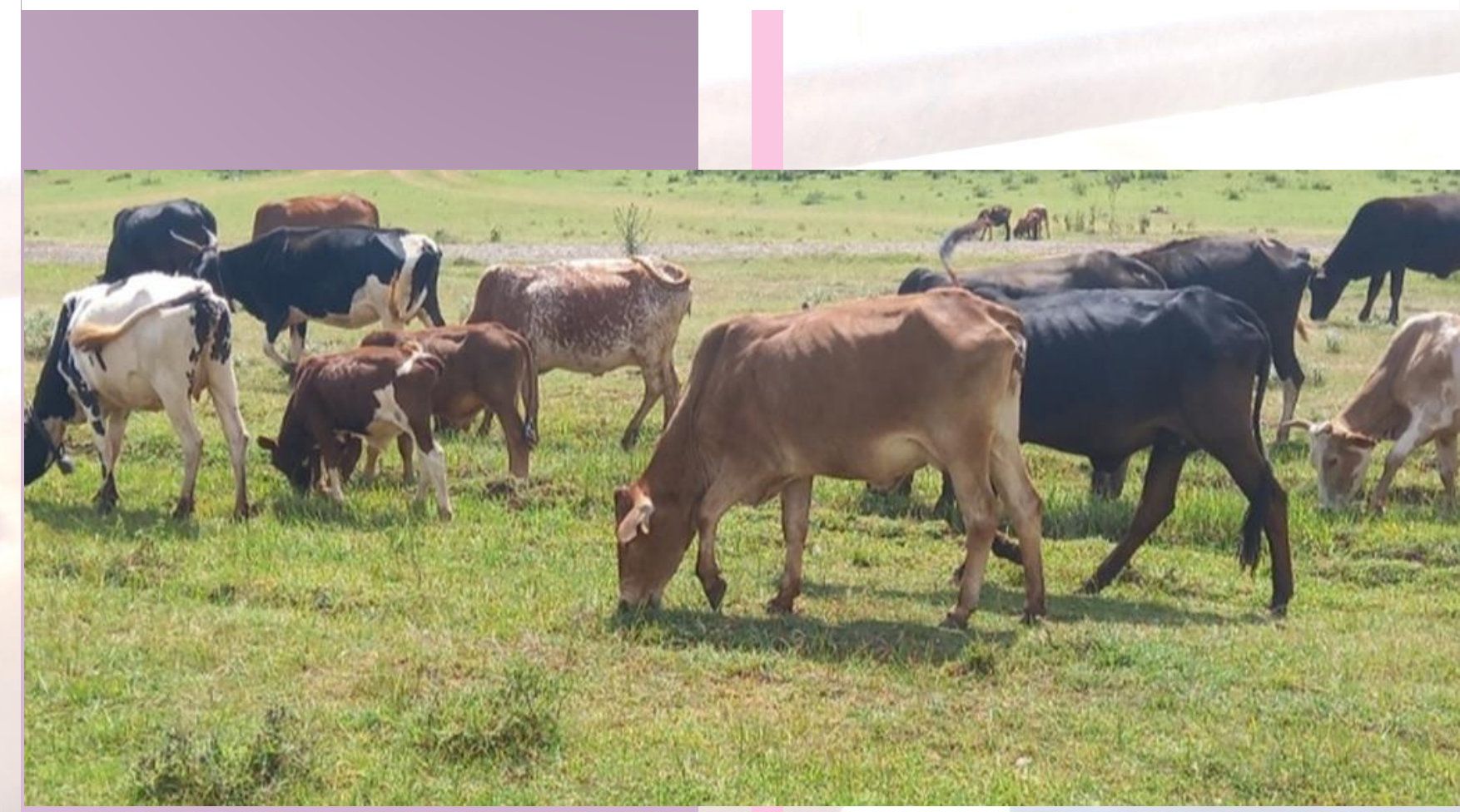

TINY:

BEAM

FUND

Dr. Maureen K. Luvanda

Postdoctoral fellow

Kenya Agricultural \& Livestock

Research Organization

P. O. Box 32-00902, Kikuyu, Kenya 


\section{Table of Contents}

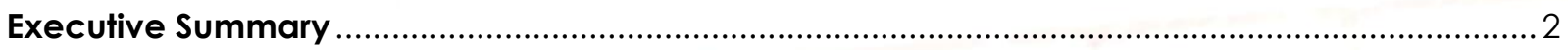

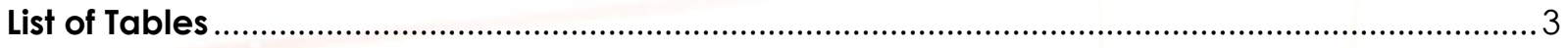

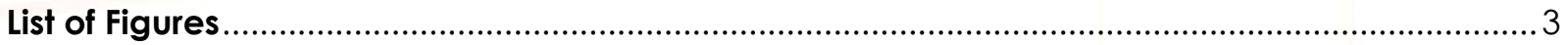

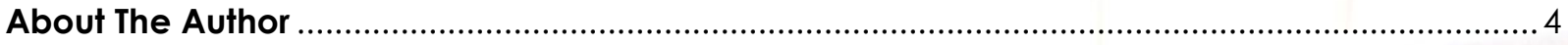

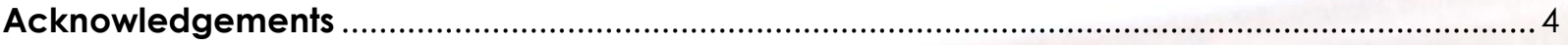

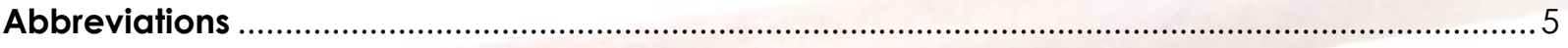

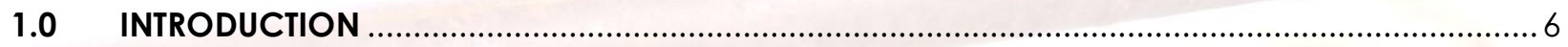

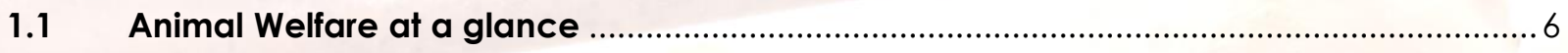

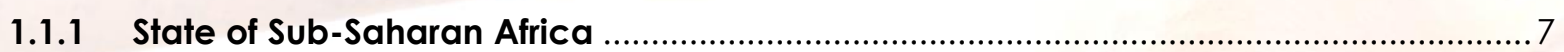

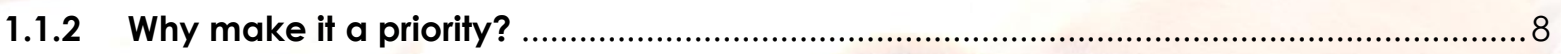

1.2 What is the importance of writing this guidance memo? ............................................... 9

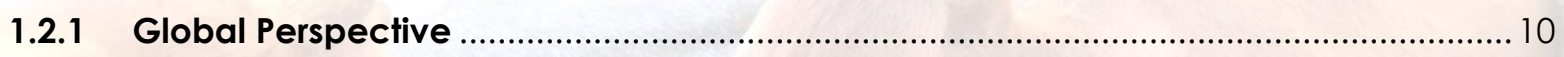

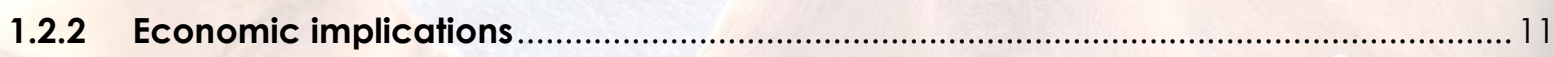

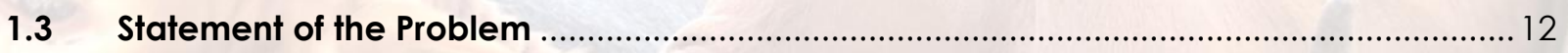

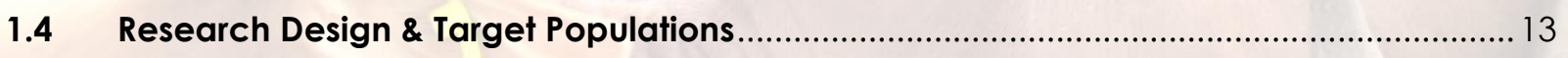

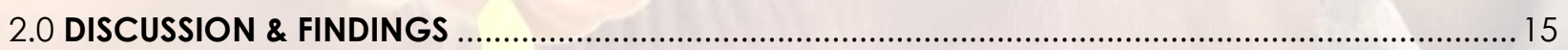

2.1 Systematic evaluation of government policies that control farm animal welfare in Kenya 15

2.1.1 So what does the Kenyan law concerning animal welfare prohibit? .......................... 18

2.1.2 Additional prohibitions \& penalties according to the Kenyan law .............................. 19

2.1.3 Other statutes within the law of Kenya concerning animal welfare .......................... 21

2.1.4 Participant opinions regarding animal welfare legislations ...................................... 25

2.2 Social norms and beliefs concerning farm animal cruelty among various communities 27

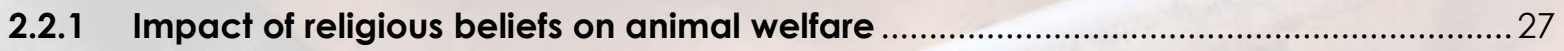

2.2.2 Impact of traditional practices on animal welfare ................................................... 28

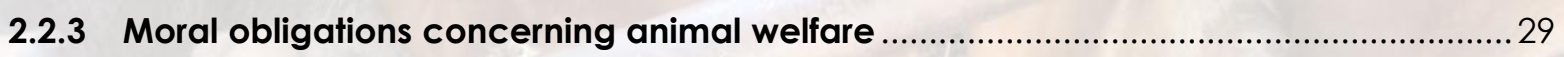

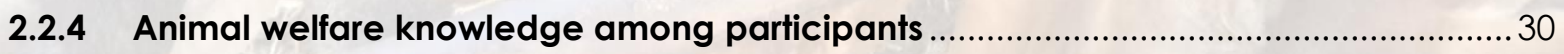

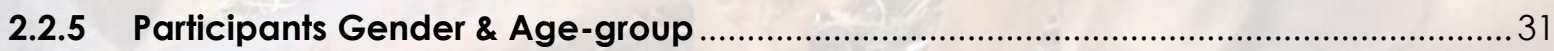

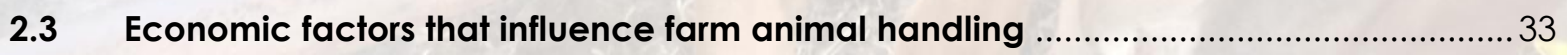

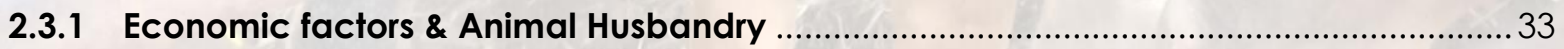

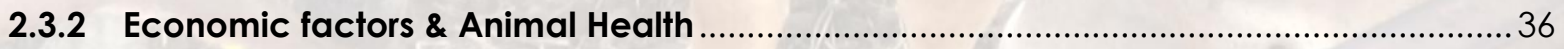

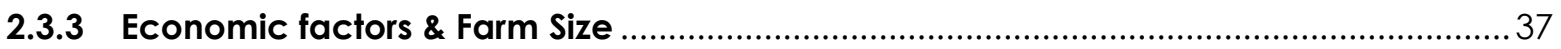

Keywords: Animal welfare, Animal Cruelty, Ethics, Kenya, Farmers, Farm animals 
3.0 CONCLUSION.

3.1 Recommendations of Practical Solutions \& Future Outlook

3.2 Where should front-line workers report incidences or suspected cases of animal cruelty? 45

4.0 REFERENCES. .46

\section{Executive Summary}

This guidance memo has been prepared to address farm animal welfare concerns in Kenya and increase the knowledge of front-line workers when it comes to standards and legislation that guide animal welfare. The focus was to evaluate aspects of animal handling, treatment and animal welfare knowledge among farmers in both small-scale and large farms in Kenya. We found that many farmers do not understand the fundamental meaning of animal welfare, most have not received specialized training in the field and many are unaware of existing legislation concerning the topic. Other stakeholders were also evaluated for comparative purposes and veterinarians, as expected, had the most knowledge about animal welfare and practices that promote it. However, several expressed concerns that the government did not put enough effort when it came to promoting public awareness or even mobilizing communities against animal cruelty. Based on the acquired information, this guidance memo was created in order to provide practical solutions when it comes to increasing animal welfare in Kenya. These suggestions include coercing the government to introduce strong policies against animal cruelty, encouraging law officers to enforce current legislation using mechanisms that are already in place and encouraging community dialogue and direct involvement of front-line persons.

Keywords: Animal welfare, Animal Cruelty, Ethics, Kenya, Farmers, Farm animals 


\section{List of Tables}

Table 1: Regions included in the study include 4 counties, 13 sub counties, 23 wards and 13 constituencies

Table 2: List of farming groups, cooperative societies, government and non-governmental organizations that provide various forms of support for Kenyan farmers

\section{List of Figures}

Figure 1: Farmer Sareiyan Kasiono who was one of the participants in the study

Figure 2: Pie chart depicting \% male vs female farmers who participated in the study

Figure 3a: Graph showing farmers age group vs working years

Figure 3b: Graph showing number of farmers who participated in the study by age group

Figure 4a: Graph depicting \% farmers rearing specific species of livestock

Figure 4b: Graph depicting \% farmers \& their reasons for engaging in farming as a profession

Figure 5: Farmer Amuja Were at his farm in Navakhalo, Kakamega County, Kenya

Figure 6: Front-line workers performing a vaccination exercise on farm animals at the Kenya Agricultural \& Livestock Research Organization, Muguga, Kenya

Figure 7: Graph depicting annual budget vs average farm size

Figure 8: Farmer Komoi ole Mukonyo at his farm in Ewuoso Oookindongi, Kajiado west in Kenya 
Cover photo: Cattle grazing at Kanai farms in Kajiado-West County, Kenya

\section{About The Author}

Dr. Maureen K. Luvanda is a postdoctoral researcher based at the Kenya Agricultural \& Livestock Research Organization. She holds a doctorate in Infection, Immunity \& Transplantation from the Medical University of Innsbruck, Austria. Her current work focuses on vaccine production for Contagious Bovine Pleuropneumonia, a cattle respiratory disease that is quite rampant in Africa. Due to her involvement in animal trials, she has developed an interest in animal welfare and prevention of animal cruelty/abuse which has led her to develop this guidance memo with direct input from front-line workers such as farmers, animal handlers and veterinarians.

\section{Acknowledgements}

The author would like to acknowledge all the participants who agreed to be interviewed for this study and the members of the bacteriology department at KALRO, specifically Dr. Monicah Maichomo, Dr. Hezron Wesonga, Dr. Moses Olum, Dr. Joseph Nginyi, Dr. Askar Jesang, Eunice Ogugo, Gideon Ruto, Richard Keshura, Collins Mwenda, Edna Masila, Nathan Lagat, and Janet Koros. 


\section{Abbreviations}

CAP Chapter

KWS Kenya Wildlife Services

OIE Terrestrial Animal Health Code

FAO Food \& Agriculture Organization

ANAW Africa Network for Animal Welfare

PAAWA Pan African Animal Welfare Alliance

IGAD Intergovernmental Authority for Development

KWS Kenya Wildlife Service 


\subsection{INTRODUCTION}

\subsection{Animal Welfare at a glance}

According to the OIE - Terrestrial Animal Health Code, animal welfare is defined as "the physical and mental state of an animal in relation to the conditions in which it lives or dies". This means that anything that disturbs the living conditions of an animal is considered animal abuse and this constitutes more than just violence. Animal abuse includes mutilation, poor animal hygiene, unkempt environment, starvation, lack of healthcare and other passive forms such as neglect, extreme confinement, inappropriate transportation, overcrowding, entertainment, inhumane capture and overloading of working animals (Mogoa et al., 2007). Passive forms of abuse occur mainly due to a lack of knowledge or sensitivity towards the life of an animal.

Mogoa et al., 2007 provide a clear definition of animal welfare and highlight the five fundamental freedoms that accompany it. The authors emphasize that both the physical and mental state of an animal determines its health and welfare status. This corroborates with the definition provided by the OIE. They also point out that academic research in animal welfare has contributed to improvement of the agricultural industry in Kenya by promoting welfare legislation and influencing improved animal conditions. They emphasize that in Kenya, animal cruelty occurs because of the following reasons 1) lack of training of animal workers in animal welfare practices 2) Existing policies and legislation are inadequate and remain unenforced 3) lack of monitoring services to ensure cases of animal cruelty are reported and prevented. 


\subsubsection{State of Sub-Saharan Africa}

In developing countries, such as those in sub-Saharan Africa (including Kenya), there is an increasing market for animal products due to urbanization making farming quite a lucrative business (Thornton, 2010). However, animal welfare is still not considered a major priority in these areas (Kimwele et al., 2011). This is quite concerning considering that it is a well-known fact that animals when treated humanely are healthier and more productive.

Therefore, since animal rearing is no longer considered an activity carried out solely in rural areas, animal farming keeps increasing at a steady state in urban areas (Alarcon et al., 2017). It is thus important to prioritize the health, physiology and living conditions of these animals. This is not only important for the animals themselves but for the general health of the entire ecosystem including humanscommonly referred to as the one-health agenda (Thumbi et al., 2015). One-health occurs through prevention of zoonotic diseases that may spread as a consequence of farm animal neglect.

Kimwele, Alarcon \& Thumbi all discuss utilization of animals from a one-health perspective. Kimwele highights one-health approaches when it comes to experimental research, Alarcon approaches the same from the perspective of urban livestock rearing and Thumbi discusses an integrated aspect which includes impact on the economy, human health as well as animal health in itself. 


\subsubsection{Why make it a priority?}

Improving the treatment and general conditions of farm animals will contribute towards optimal production of commercial products such as milk and eggs thus ensuring that food security within the region remains stable (Njisane et al., 2020). In this effort, different methods and practices have been utilized to improve animal welfare including "conditioning" methods and introduction of relevant legislations that demand humane practices when it comes to interaction with animals (Edwards-Callaway \& Calvo-Lorenzo, 2020).

In addition, animal welfare has also been reported to be a measurable entity based on environmental conditions and the physical properties of the animal (Broom, 1991). The area of animal welfare and its ethics is still considered a fairly new concept encompassing more than just the physiological state of the animal in terms of health (Manning et al., 2021). It is important to prioritize this area not only for the benefit of the animal but for the benefit of all front-line workers who interact with these animals on a daily basis and the community at-large (Rioja-Lang et al., 2020).

Njisane, Edwards-Callaway, Calvo-Lorenzo, Broom \& Manning all review, discuss and highlight issues concerning animal welfare in the United States, Australia and in African communities. 


\subsection{What is the importance of writing this guidance memo?}

This guidance memo intends to provide insight into the current condition of farm animal welfare in Kenya thus providing a backbone for the introduction of similar 'animal welfare promoting' activities within the country and in Africa at large, triggering a level of concern for all parties involved. It will also explain in simpler terms the various legislation and policies that are currently in place in order to make it easier for non-academic front-line animal workers to understand what exactly encompasses animal welfare and the expectations when it comes to handling and treatment of animals. To that end, comparisons were carried out between small-scale vs large-scale farms to discern contrasting contexts and a comprehensive study of available literature was carried out to evaluate available information about the current status of animal welfare in Kenya.

Funding to write this guidance memo was provided by Tiny Beam Fund, Inc. (https://tinybeamfund.org). 


\subsubsection{Global Perspective}

The world agricultural industry has demonstrated time and again that they prioritize animal production over animal or human health (Greger 2011). Recent reports have even demonstrated that largescale animal production facilities not only lead to detrimental animal health but they contribute towards health deterioration in factory workers as well as the inhabitants of surrounding communities (Greger \& Koneswaran, 2010). Further to that, transportation of livestock over long periods of time and at long distances has been described as opportunities to spread diseases by FAO (Greger, 2007). Fortunately, there has been a global outcry for the welfare of animals including efforts made by the World Animal Protection Organization which is involved with activities against close confinement of animals by advocating for free movement of animals and thus increasing their living standards.

In 1958 the "Humane Methods of Slaughter Act" " was passed in the US and is currently enforced by the USDA Food Safety and Inspection Service. This law requires that all slaughter houses comply to handle animals for slaughter in a gentle and humane manner. This shows when it comes to animal welfare at a global perspective, concerns extend even beyond the farm and towards biotechnology and other advanced technological discoveries which may affect the animal adversely and may even lead to increased zoonosis. 


\subsubsection{Economic implications}

Due to the rising increase in consumption of meat and dairy products in Africa, farm animals contribute significantly to the agricultural and national GDP (Molomo \& Mumba, 2014). Since 2018, the Africa Network for Animal Welfare (ANAW) has collaborated with the United Nations Environment organization to advocate for animal welfare across African countries with active participation from direct stakeholders as well as civil societies. The partnership has also led to development of the Pan African Animal Welfare Alliance (PAAWA) which advocates for the welfare of animals to improve economic output all across Africa.

In 2017, Kenya developed a strategic plan to address animal welfare concerns in the country for the improvement of the population's economic situation. This was done through the Intergovernmental Authority for Development (IGAD) organization. They developed documented action plans for the years 2017-2022. These included the "Kenya National Animal Strategy \& Action Plans" and "Kenya National Animal Welfare Strategy".

Molomo \& Mumba's research demonstrates how farm animals contribute significantly to the Gross Domestic Product of the entire continent of Africa where millions of people depend on them for food and income. Despite that, animal welfare is still a largely neglected issue in the continent. They therefore suggest that the entire region should strive to understand issues concerning animal welfare, thus increasing animal productivity and product quality.

Keywords: Animal welfare, Animal Cruelty, Ethics, Kenya, Farmers, Farm animals 


\subsection{Statement of the Problem}

Front-line persons who are constantly handling animals need to have a deeper understanding of the best practices to apply when it comes to improving the welfare of their animals.

Having had the opportunity to work in different continents (Asia, North America, Africa and Europe), I have had a chance to observe the similarities and differences in animal handling practices in different economic and cultural settings.

The general observation is that animal welfare standards appear to correlate extensively with a higher economic disposition, an assumption that we hoped to debunk in this study. It was therefore imperative to gain the views of those directly involved in handling of farm animals in order to understand the situation on the ground when it comes to animal welfare practice, concerns and general knowledge. 


\subsection{Research Design \& Target Populations}

This study applied qualitative methods which include survey questionnaires (semi-structured interviews) conducted based on purposive non-probability sampling.

It consisted of two sections where section one focused on the demographic data of the respondents and section two addressed animal cruelty/abuse and welfare concerns. Naturalistic observations were also made which allowed a proper definition of the scope of the topic and the focus to be on specific underlying issues that are of greater importance.

The methods allowed gathering of required information as well as observation of farmers and front-line workers in their usual everyday habitats and routines as well as detailed evaluation of other workers. It also allowed the opportunity to evaluate situations based on the opinion of those that really matter. The questions asked were based on the Welfare Quality Protocols, farm assurance and established legal standards. 
Exploration of public literature to acquire an academic perspective was also done to ensure a deeper understanding of government policies and practices surrounding animal welfare and possible solutions. The target population included smallscale and large-scale farmers, veterinarians and other front-line workers such as animal handlers, herdsmen, academic experts and government officials. A total of 126 farms were visited in the target regions depicted in Table 1. Participation was voluntary and all participants provided informed consent before getting involved. Unless otherwise stated, all data was handled confidentially. 


\subsection{DISCUSSION FINDINGS}

\subsection{Systematic evaluation of government policies that control farm animal welfare in Kenya}

Although academic materials and publications concerning animal welfare specific in Kenya is limited, the government of Kenya promulgated a new constitution in 2010 which has a provision for upholding animal rights by preventing unnecessary cruelty and suffering.

It outlines the role the government should play when it comes to promoting animal welfare specifying that the national government is responsible for protection of wild animals while the county governments are responsible for livestock and domestic animals (Constitution of Kenya, 2010).

Two years later, the "Prevention of Cruelty towards Animals Act" was revised and approved (Act No: CAP. 360). This act is the cornerstone of all animal welfare laws in Kenya and was initially passed in 1953 with revisions in 1962,1964, 1969,1979 and of course 2012. It was published 
by the National Council for Law Reporting with permission from the Attorney General's office.

It consists of 4 parts where the first part introduces the law, the second part discusses actions that are considered offences when dealing with animals, the third part addresses experimental use of animals such as in relation to scientific research and the last part deals with additional provisions that may have been overlooked by the other sections.

Therefore, except for part 3, all the other parts are relevant to farmers and this memo will summarize the most relevant information in a manner that is straightforward and easier for front-line workers to understand. 
Table 1: Regions included in the study

\begin{tabular}{llll}
\hline County & Subcounty & Ward & Constituency \\
Vihiga & Sabatia & Busali & Sabatia \\
Vihiga & Sabatia & Chavakali & Sabatia \\
\hline Vihiga & Sabatia & West sabatia & Sabatia \\
Vihiga & Sabatia & North maragoli & Sabatia \\
Vihiga & Sabatia & Wodanga & Sabatia \\
\hline Vihiga & Vihiga & Central maragoli & Vihiga \\
Vihiga & Emuhaya & North East bunyore & Emuhaya \\
Vihiga & Hamisi & Tambua & Hamisi \\
Vihiga & Hamisi & Gisambai & Hamisi \\
Vihiga & Hamisi & Shiru & Hamisi \\
Kakamega & Lurambi & Mahiakalo & Lurambi \\
Kakamega & Navakhalo & Shikorami / Esumaiya & Navakhalo \\
Kakamega & Navakhalo & Ingotse Mutihu & Navakhalo \\
Kakamega & Malava & South Kabras & Malava \\
Kakamega & Shinyalu & Isukha central & Shinyalu \\
Kakamega & Shinyalu & Murhanda & Shinyalu \\
Kajiado & Kajiado west & Ewuaso Kedong & Kajiado west \\
Kajiado & Kajiado west & Magadi & Kajiado west \\
Kajiado & Kajiado west & Ewuaso Oonkidongi & Kajiado west \\
Kajiado & Kajiado central Dalalekutuk & Kajiado central \\
Kajiado & Kajiado south & Entonet/Lenskim & Kajiado south \\
Nairobi & Embakasi East & Utawala & Embakasi East \\
Kiambu & Kikuyu & Kinoo & Kikuyu \\
\hline
\end{tabular}

Table 1: Regions included in the study include 4 counties, 13 sub counties, 23 wards and 13 constituencies 


\subsubsection{So what does the Kenyan law concerning animal welfare prohibit?}

According to the constitution, the law prohibits:

- Cruel beating of animals,

- Ill-treatment resulting in pain or other forms of suffering,

- Overloading of transport animals,

- Torturing of animals,

- Unjust terrifying of animals,

- Infliction of unnecessary pain and suffering to animals,

- Use of sick/injured/tired animals for work,

- Unnecessary confinement of animals,

- Starving/underfeeding or denying water to animals under your care,

- Neglecting animals under your care,

- Keeping of animals in unhygienic conditions,

- Refusing to meet the health-related needs of an animal such as vaccination or treatment of diseases,

All these offences are punishable under the Kenyan law as "guilt of the offence of cruelty" which results in approximately 6 months of jail time or a fine of less than KShs.300, 000 or even both penalties. 
The law also prohibits:

- Administering dangerous drugs or poisonous substances to animals,

- Performing or allowing illegal surgery to be performed to an animal,

- Refusing to give mercy to an animal when the circumstances demand it

- Illegal hunting and killing of animals.

\subsubsection{Additional prohibitions \& penalties according to the Kenyan law}

Here we mention other activities that the law prohibits concerning animal cruelty and the fine/punishment incurred if a person is found guilty of an offence. First, it is punishable by law to participate in any way shape or form in the act of fighting or baiting of an animal.

\section{This offence may lead to jail time of approximately 6} months or a fine of KShs.3, 000 or both.

Trapping of animals using devices that lead to their injury or demise is also forbidden and a fine may be imposed on the culprit. Further to that, the materials utilized to manufacture the trap and the trap itself may be confiscated by law enforcement officers. 
Abandonment of an animal when it is in mutilated condition, sickly, in an unsafe area or a confined space where it is unable to escape, cruel training of animals for exhibitions/competitions/performances or contests in a manner that induces pain and suffering, slaughtering of animals in a cruel manner or killing of an animal while other animals are standing by and able to see are also considered crimes.

\section{These crimes are punishable by approximately 3} months prison time or KShs.2, 000 fine or both. In addition, any items that were used to commit the crime may be confiscated by law enforcement.

Films/movies that are shown to the public should never exhibit any forms of animal cruelty. Exposure of animal cruelty through film in public may lead to prison time not exceeding 3 months and a KShs.2, 000 penalty or both. Hawking of animals in a manner that promotes their discomfort, pain or any type of suffering is also punishable by law and attracts a fine of KShs.500.

Animal owners who allow their animals to be mistreated in any of the forms mentioned above either directly or indirectly are also held responsible by the court of law. It is the duty of the animal owner to protect his animals and failure to do so will attract punishment by law 
enforcement or even removal of the animals from the custody of its owner. Further to that, any expenses incurred during confiscation of the animals or any other directives from the court will be transferred to the owner. The convicted owner may even be barred from ever owning/possessing/handling animals in the future if the court is convinced that exposure of animals to the culprit may lead to further offence.

\section{Failure to respect the rule of law would lead to approximately 6 months prison time or a fine of KShs.3, 000 or even both.}

\subsubsection{Other statutes within the law of Kenya concerning animal welfare}

Other statutes found within the Laws of Kenya that address animal welfare issues include "Animal Diseases Act CAP 364" which covers the actions to be taken by an animal handler should the animal be afflicted by disease. It stipulates that a handler is expected to protect his and other's animals from contagious diseases therefore obligated to quarantine any of his/her flock in the event of a suspected outbreak.

$\mathrm{He}$ / She is also obligated to inform the public through the nearest authority figure of a suspected disease outbreak. Should the animal 
succumb to death due to the suspected disease, disposal should be carried out under the directions of a qualified veterinary officer.

Under this act, they also stipulate that certain vaccinations such as Rinderpest for cattle are compulsory by law and a veterinarian should be consulted regarding these immunizations.

It also stipulates that any feed given to animals must be free of disease and healthy for consumption by the animal. This act also states that animals acquired through importation from any other country must be tested and treated for any possible diseases before being allowed to join the general population.

\section{Any activity that violates this act will lead to punishment by approximately 12 months} imprisonment or less than or equal KShs.30, 000 fine.

The "Branding of Stock Act CAP 357" is also a statute among the laws of Kenya which stipulates positions in an animal's body where branding is permissible for purposes of registering stock. It also specifies the types of animals that may be branded which include cattle, horses, camels, sheep and goats and it directs where branding irons may be procured. 
The "Rabies Act CAP 365" is another statute in the constitution of Kenya that has been provided to reduce the cases of rabies within the country. It provides authoritative figures such as law enforcement officers, veterinary officers, administrative officers or inspectors the right to capture and impound an animal suspected to have rabies or even kill it if found in an area that is termed a "rabies control area". This generally falls in the docket of pet animals such as dogs and cats rather than livestock.

\section{In the case of a rabies infected animal, an owner who} does not control his animal is liable for arrest or punishment by law. The fine accompanying a breach in this law is KShs. 5 per each day since a report has been made until the day the owner controls his animal.

If an owner refuses to control his diseased animal he may be jailed for 3 months or pay a standard fine of KShs.2, 000 or both. Areas that are declared rabies control areas include Mukogodo Reserve in Nanyuki District, Tharaka, Nyambene and Northern Grazing area locations in Meru, Machakos County (except for the parts shown bounded in red in the Boundary Plan Number 500), Western Province, Nyanza 
Province, Kitui District in the part of Kamba land that is situated there as well as B.2 Yatta Government Land and Eastern Government Land. Within the first 3 months after an area has been declared a "Rabies control area" animal handlers and owners are expected to keep their pets confined within an enclosed area such as a kennel between the hours of $7.00 \mathrm{pm}$ and $6.00 \mathrm{am}$. At other time-periods the animals should be kept on a leash.

\section{Failure to comply with the mandated quarantine may} result in 1 month prison time or a fine determined by the court.

Lastly, obstructing of law enforcement officers when they are in the process of carrying out their duties leads to a punishment of at least 6 months prison time or KShs.3, 000 fine or both. The Supreme Court reserves the right to finalize any decisions especially concerning judgements. False accusations and unfair judgements can also be appealed in this court within 7 days. 


\subsubsection{Participant opinions regarding animal welfare legislations}

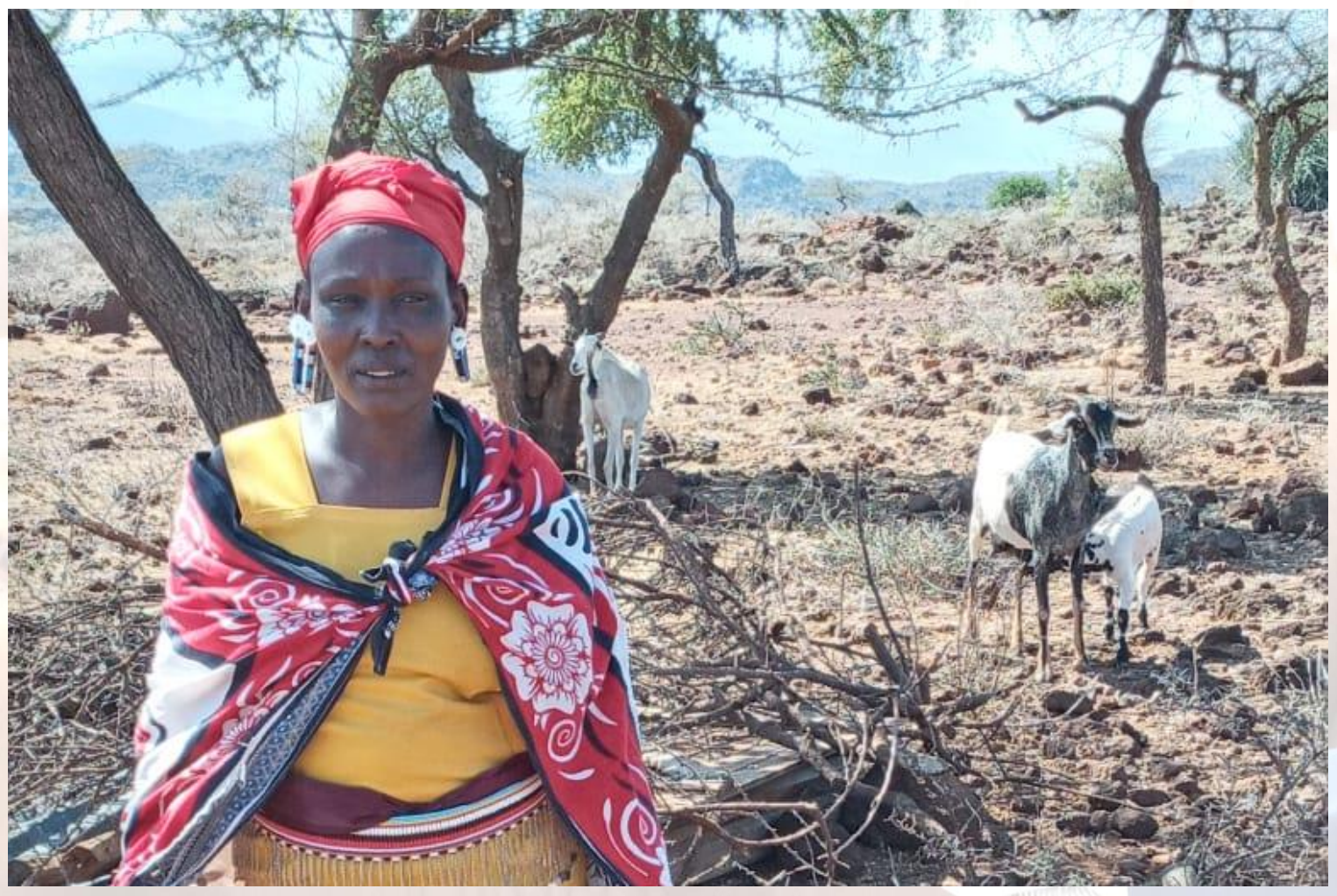

Figure 1: Farmer Sareiyan Kasiono, who was one of the participants in the study at her farm in Kajiado, Kenya

Only $24.6 \%$ of the farmers included in this study were aware of the above highlighted government legislations concerning animal welfare with most being familiar with anti-poaching initiatives by the Kenya Wildlife Services (KWS). 
91.3\% of the respondents indicated that they would support law enforcement when it came to promoting animal welfare and that violations should be punishable by law; especially in situations where handlers subject their animals to torture. However, they all agreed that enforcement of legislation concerning animal abuse would be more effectively implemented if there was proper awareness training of animal handlers.

What was concerning to some of the participants was that the Rabies Act allowed for execution of animals. It was also concerning that leaving poisonous substances within the environment which may lead to the death of an animal is punishable by a fine of only KShs.200. The "Branding of Stock Act" was also criticized by some front-line workers for not providing any solid legislature concerning branding of animals in a humane manner to address animal cruelty.

Many were of the opinion that harsher penalties should be introduced to increase vigilance when it comes to protecting animals from manmade environmental harm. Although these policies and legislations concerning animal welfare exist in Kenya, they are considered inadequate (Mogoa et al 2007) and not well enforced at the grassroot level. 


\subsection{Social norms and beliefs concerning farm animal cruelty among various communities}

African culture and religion appeared to play a great role in influencing how farmers in Kenya handle their animals.

\subsubsection{Impact of religious beliefs on animal welfare}

Those practicing the Christian faith referred to the parable of tending to the animal which had fallen into a ditch during the Sabbath meaning that their faith encourages them to help animals despite the circumstances.

Some referred to the book of Genesis where God commanded man to take care of all creatures on earth including the animals in the Garden of Eden. Some said that they give animals as offering to the church especially for tithe purposes and also in those denominations that submit the first born son to the pastorate right after birth. Animals therefore play a huge role in religious practices that simulate a covenant with God. 


\subsubsection{Impact of traditional practices on animal welfare}

Traditional beliefs placed animals on a pedestal especially among the Maasai community indicating that they play a very important role in their society.

Several communities have traditions that dictate that animals are used as gifts such as during dowry/bride-price negotiations, condolence tokens during funeral arrangements and also for entertainment purposes such as regional bull-fighting sport events.

Animals are regarded as a source of wealth and security by several communities therefore they also serve as a sign of high social status which can be passed on from one generation to the next. They are also used to perform certain rituals during rite of passage ceremonies and different tribes have various informal systems in place for punishing those who mistreat the animals. Farmers within these communities have established clear standards to ensure good care of their animals even in their absence. 


\subsubsection{Moral obligations concerning animal welfare}

In communities that lack traditional systems that promote animal welfare, it was encouraging to find that although several of the respondents (69.84) have not witnessed animal cruelty incidences, $\mathbf{8 9 . 7 \%}$ of them confirmed that if a situation arises where they observed any form of animal cruelty, they would immediately report it to the authorities

These authorities include the police, agricultural officer, administration, veterinary offices/officer, area chief/assistant chief, government officer/office, village elders or to the farm owner in case it's a situation involving an employed animal handler.

$30.9 \%$ said they would even go further and sensitize/advice the concerned parties about the importance of animal welfare and advocate for zero cruelty and other animal rights, while $13.5 \%$ would actively stop the vice even if the authorities delayed to intervene.

This indicated that collectively front-line persons are well aware of their moral obligations when it comes to animal welfare and prevention of animal cruelty. 


\subsubsection{Animal welfare knowledge among participants}

Those respondents who admitted that they would hesitate to intervene confirmed that the main reason was a lack of formal training in animal welfare which affected their confidence in the matter and a lack of information about where exactly they can report the issue.

However, only $14.3 \%$ indicated that they were aware of emerging and current animal welfare concerns.

Those who had the knowledge mentioned that the issues below are some of the most common and major animal awareness concerns they have observed in their line of work.

- Overworking of labor animals such as oxen/donkeys,

- Use of animals for entertainment purposes,

- Unnecessary drugging of animals to make them more or less aggressive,

- Beating/mutilation of animals to settle old scores,

- Starving/poor ratio/unhygienic/ feeding of animals,

- Tethering animals in place for extended periods of time,

- Provision of confined/dirty living spaces,

- Slaughtering of animals without euthanasia, 
- Inappropriate castration of animals, lack of water provision thus subjecting animals to extreme thirst,

- Rearing of poultry using battery system,

- Transporting animals while in cages,

- Overloading of transport/animals used for labor,

- Refusing to treat animals when sick (the most common being refusing to trim overgrown cattle hoofs leading to injuries and sometimes amputation and late dehorning of mature cattle leading to infections and even death)

- and slow response when it comes to protecting animals from predators

$34.9 \%$ of them were familiar with existing practices and movements that promote animal welfare such as the "Tunza Punda Clinics Initiative" which promote humane treatment of donkeys, seeking of veterinary services whenever an animal is sick or if there is an outbreak of known or unknown disease.

\subsubsection{Participants Gender \& Age-group}

On a positive note, the gender gap appeared to be rapidly closing in the field of livestock farming with female farmers making up $47.6 \%$ of the respondents in this study compared to males who made $52.4 \%$ as shown in the pie chart in Figure 1. 
Pie chart of perecentage gender frequency
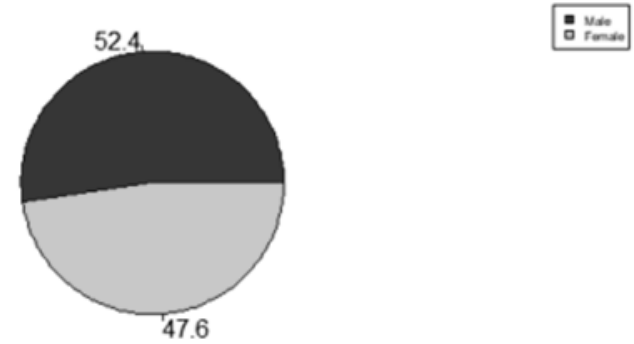

\begin{tabular}{|l|l|l|}
\hline Gender & $\mathbf{n}$ & Percent \\
\hline male & 66 & 52.4 \\
\hline Female & 60 & 47.6 \\
\hline & & \\
\hline
\end{tabular}

Figure 2: Pie chart depicting percentage of male vs female farmers who participated in the study.

It was also interesting to observe that when grouping the number of farmers based on age-group (this information informed the study cohort included in this study), young people between the ages of 2029 were well represented but middle aged groups between the ages of 40-49 were the most active participants as seen in Figure 3.

A

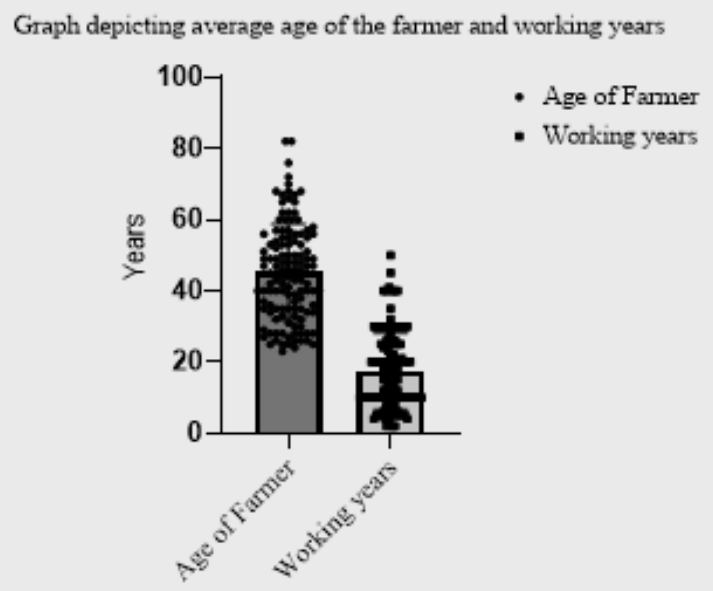

B

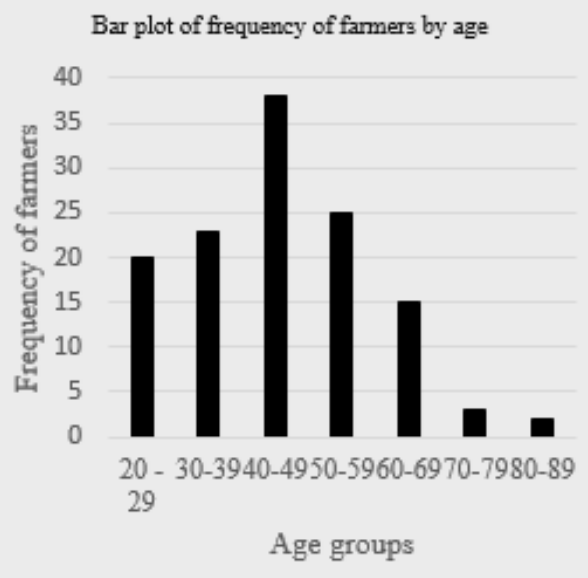

Figure 3: A) Graph showing the age group of farmers who participated in this study and average working years. B) Graph showing number of farmers who participated in the study group by age group. The age group between $40-49$ years appeared to be the most actively involved in farming profession. 


\subsection{Economic factors that influence farm animal handling}

Since several global organizations advocate for transitioning to plantbased diets, we evaluated the willingness of farmers to switch from animal farming to purely crop farming. A whopping $72.2 \%$ said they would not switch due to economic factors and climatic conditions.

This was understandable because it correlated well with the fact that less than $5 \%$ of the farmers included in this study had other sources of income. Therefore, without adequate funding it would be difficult to supplement inadequate water, unfavorable weather conditions and soil infertility. However, some expressed a desire to carry out mixed farming activities.

\subsubsection{Economic factors \& Animal Husbandry}

Most of the farmers (88.1\%) who participated in the study favored the rearing of cattle compared to other species of animals as shown in Fig. 4. This appeared to be another decision based on economic factors with $>90 \%$ farmers expressing that their main purpose of farming is to generate income and provide food for their families. 
Therefore, since there is an increase in meat and milk consumption with most of the production obtained from cattle, it would make more economic sense for the farmers to lean more towards rearing cattle than any other animal species. However, goat, sheep and poultry were also more preferred than other animals such as pets making up $41.3 \%, 33.3 \%$ and $27.8 \%$ of animals, respectively.

Donkeys on the other hand which are the most popular animal for manual labor in Kenya appeared to make up only $20.6 \%$ indicating that animal meat and milk production is prioritized labor activities. Over $58.7 \%$ considered animal welfare a very expensive affair with many farmers preferring to allow their animals to roam (free-range) in order to feed on existing vegetation. Buying of animal feed and clean water was mainly done during the dry season and in situations where there were animals in isolation/quarantine during a disease outbreak. As depicted in Fig. 4B most farmers (93.6\%) engaged in the animal rearing to generate income. Others did it for food products (80.2\%), to get manure for land cultivation (10.3\%), for security purposes (63.6\%), as a passion (14.3\%) and to provide transport/labor (39.7\%). 
A

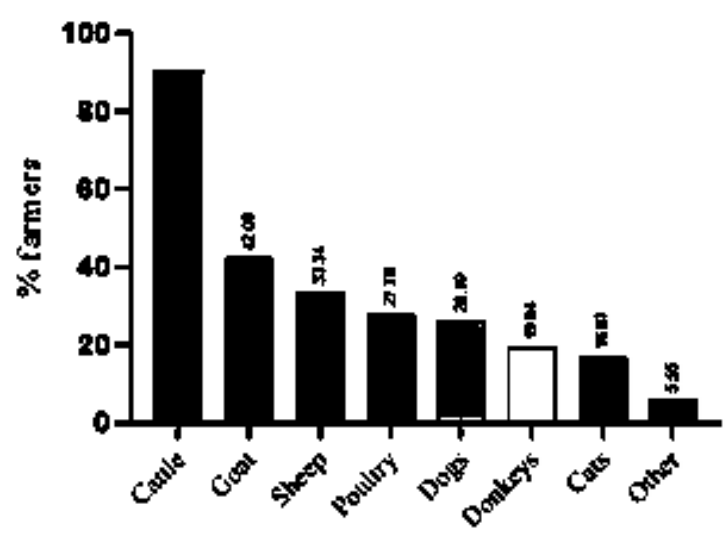

B

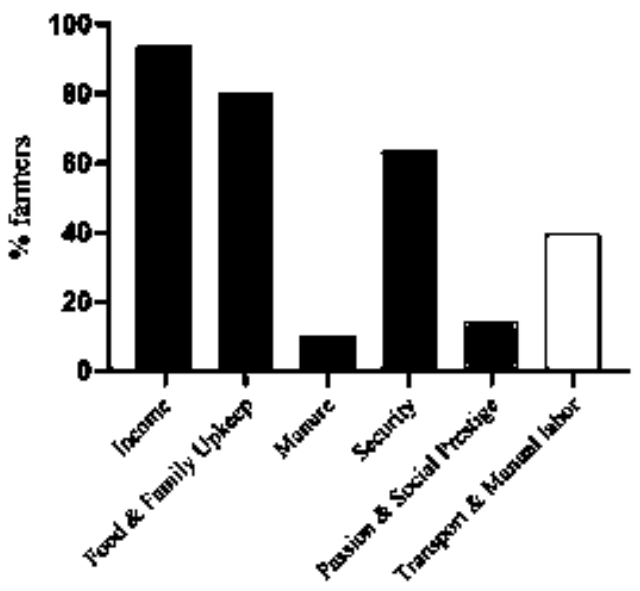

Figure 4: A) Graph depicting the percentage of farmers (y-axis) rearing specific species of livestock (x-axis). B) Graph depicting the percentage of farmers (y-axis) and their reasons for engaging in farming as a profession (x-axis).

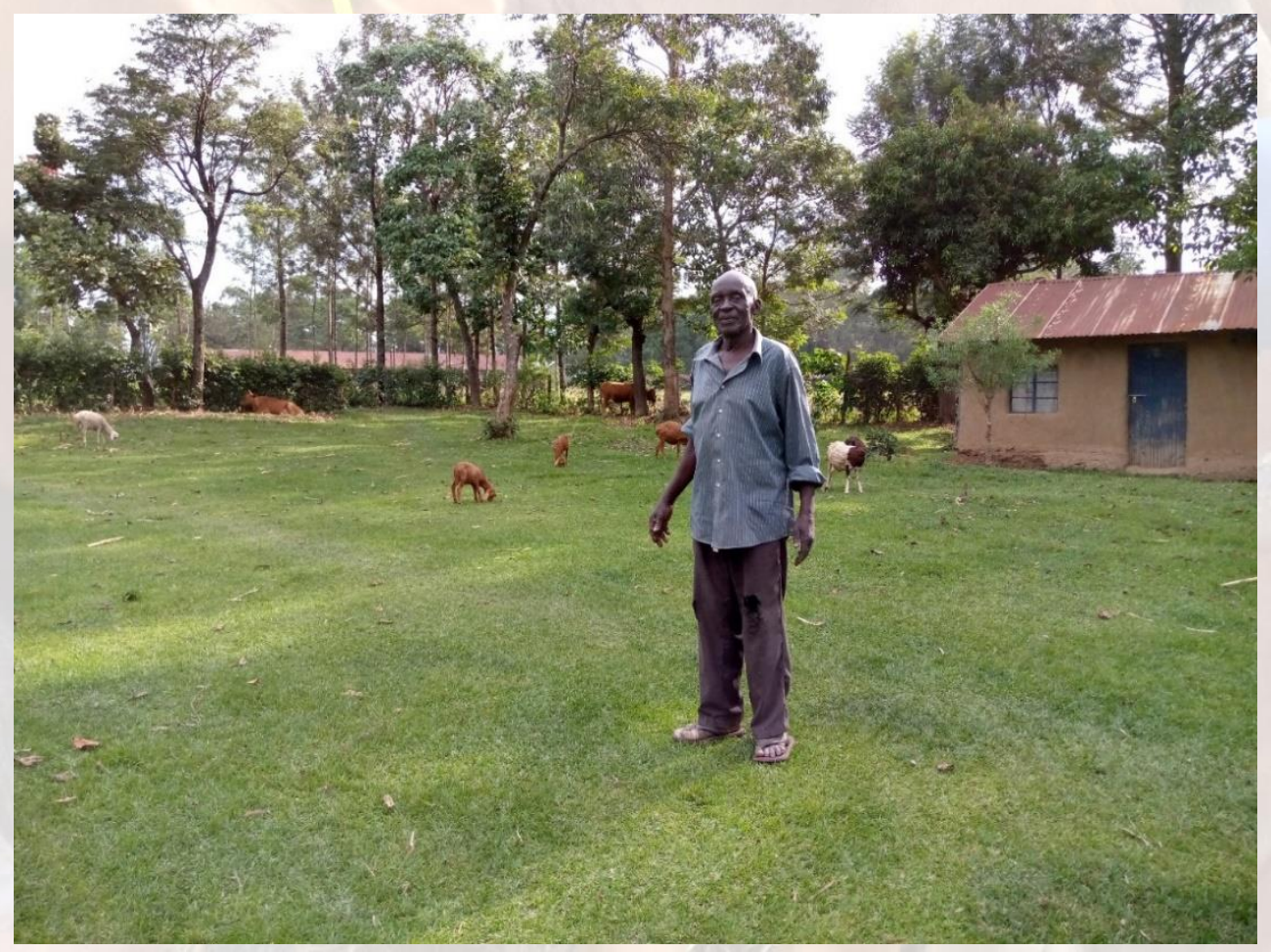

Figure 5: Farmer Amuya Were at his farm in Navakholo, Kakamega County, Kenya 


\subsubsection{Economic factors \& Animal Health}

Economic factors seemed to also impact health care decisions such as access to veterinary services as well as vaccinations. Some farmers neglected to vaccinate their pets because priority was given to income generating livestock.

Despite these challenges $72.2 \%$ of respondents admitted to seeking professional veterinary services whenever their animals fell sick or required vaccination. Cattle were consistently vaccinated against common diseases such as Foot \& Mouth Disease, East Coast Fever, Brucellosis, Peste des petits ruminants, Lumpy Skin Disease, Black Quarter, and Enterotoxaemia. Poultry farmers routinely vaccinated their birds against Newcastle disease, Fowl pox, Fowl typhoid and Gumboro.

Protection against parasites which is also dependent on economic factors also is mainly carried out on a weekly basis using various control measures such as knapsack spraying of anti-fungal and insecticidal medications, handpicking of ticks, cattle dipping, multivitamin bolstering and regular deworming. 


\section{Therefore neglect, which is the most common type of} animal abuse, is also enhanced by economic constraints and this can influence the health of animals in significant ways.

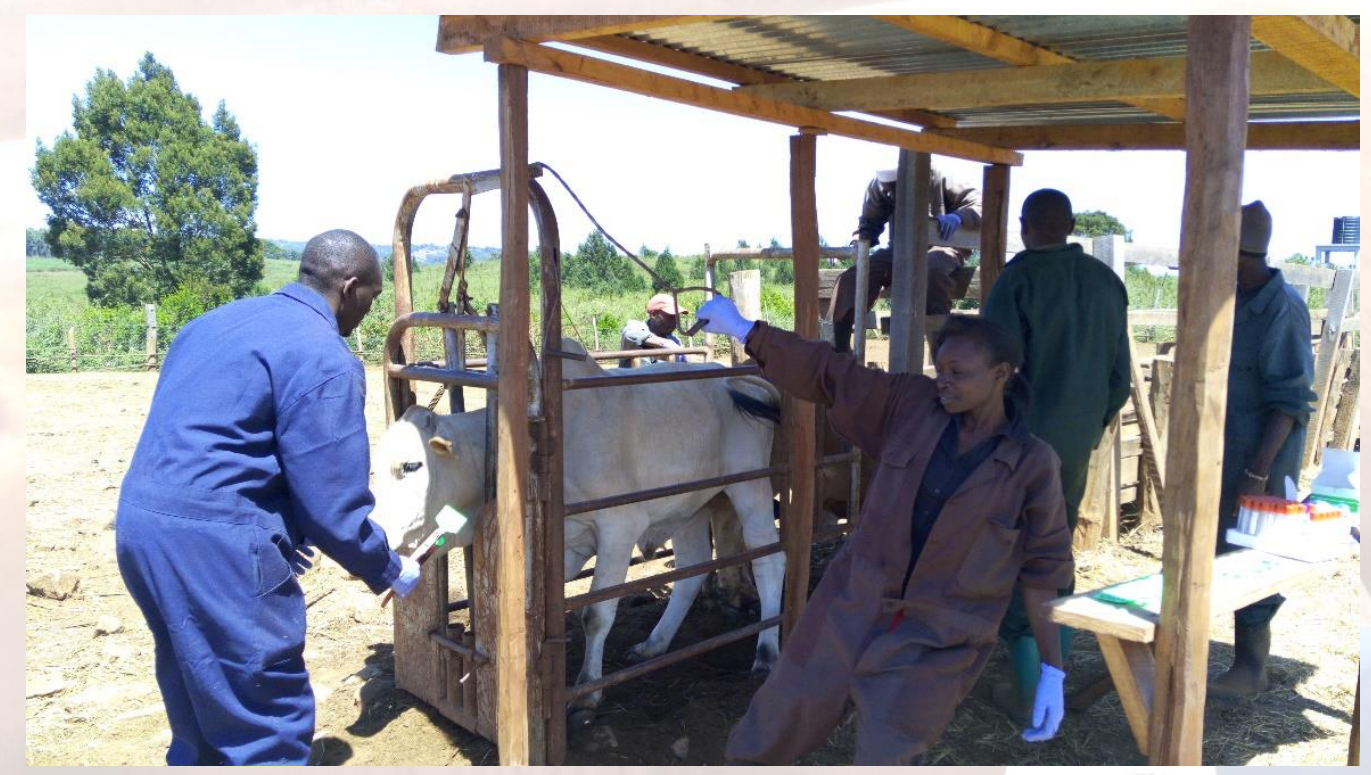

Figure 6: Front-line workers (Moses Orwe, Eunice Ogugo \& other animal handlers) performing a vaccination exercise on farm animals at the Kenya Agricultural \& Livestock Research Organization, Muguga, Kenya. (Tiny Beam Fund Inc.

\subsubsection{Economic factors \& Farm Size}

Majority of the farmers included in this study have a farm of less than 150 acres with an average farm size of 56 acres per farmer. This was determined by the economic capacity of the individual farmer. 
The average annual budget per farm was determined to be KShs.170, 000 per annum which is approximately KShs.500 per day. Although 97.6\% of them personally own their farms, with only $2.4 \%$ owned by government or the community, there was still a strong indication that many are facing economic constraints because $33.33 \%$ of them received financial support as a grant or loan.

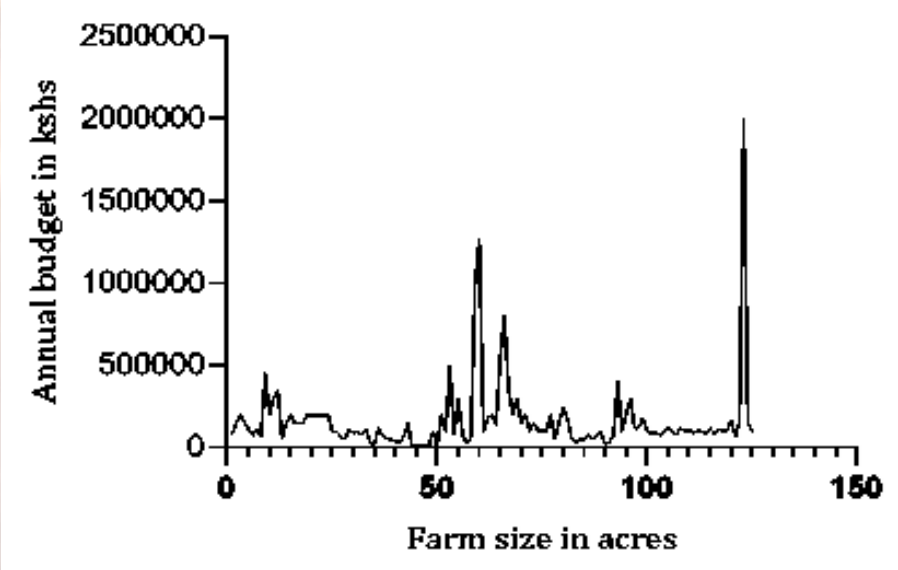

Figure 7: Graph depicting annual budget (y-axis) vs average farm size (x-axis) of participants included in the current study

Financial support was received from either from a farming group, cooperative society, and non-governmental organizations or via direct government assistance as shown in Table 2. Government-sponsored agri-business loans, business training and livestock disease 


\section{vaccination programmes are quite common as well as programmes that provides fingerlings and feeds to various fish farmers.}

\begin{tabular}{|c|c|}
\hline Farming Groups & $\begin{array}{l}\text { "Jitegemee women's group", “Muzulia Watane S.H.G”, } \\
\text { "Chofumbo Agro-ventures", "Imbinga S.H.G", "Nyumba Kumi } \\
\text { Initative for Animal Anti-theft", "Raa women's } \\
\text { group", "Weshula Farmers Group", "Furaha Initiative”, } \\
\text { "Mukangu Farmers Society", "Dellosa Sunfields FCS Ltd", } \\
\text { Sabatia Micro- \& Small Enterprise Association" and "Shinyalu } \\
\text { Poultry Entreprenuership Group". }\end{array}$ \\
\hline Co-operative Societies & $\begin{array}{l}\text { "Sabatia Dairy Co-operative Society", "Muvishi Dairy Co- } \\
\text { operative Society", "Catholic Friend \& Pentecostal Support", } \\
\text { Murhanda Co-operative Society", "Hamisi Co-operative } \\
\text { Society" and "South Kabras Dairy Cooperative Society". }\end{array}$ \\
\hline $\begin{array}{l}\text { Non-governmental } \\
\text { organisations }\end{array}$ & $\begin{array}{l}\text { "Harvest of Hope","Goldifarm funds", "Sweet Potato } \\
\text { Establishment \& Feeds", "Community Health Volunteer group ( } \\
\text { Vegetable Seed Distributors)", "Mainyoito Pastoralists } \\
\text { Integrated Development Organization (MPIDO)" and "One Acre } \\
\text { Fund. }\end{array}$ \\
\hline Government & $\begin{array}{l}\text { "Cash Transfer for Orphans and Vulnerable Children" (CT-OVC) } \\
\text { Initiative, "Uwezo Fund", County government "One Cow } \\
\text { Initiative", "Poultry Subsidy Programme" ,"Kenya Climate } \\
\text { Smart Agriculture Project" (KCSAP). }\end{array}$ \\
\hline
\end{tabular}

Table 2: List of farming groups, co-operative societies, government and non-governmental organizations that provide various forms of support to Kenyan farmers 


\subsection{CONCLUSION}

The conclusions made in this study took into account the opinions of front line workers in the field of animal welfare therefore incorporating both internal and external perspectives.

This guidance memo provides evidence that animal welfare standards and practices are mainly influenced by culture, pre-established practices, community involvement, economic strengths and perhaps just animal handling awareness at a rudimentary level.

The findings clearly illustrate that there should be an improvement in the handling and rearing of animals which can only be achieved by contributing towards a better understanding of practices that promote animal welfare.

From the work we can see that animal welfare knowledge is only made complex by the lack of access to information leading to inadequate knowledge concerning the topic by the concerned parties.

Especially front-line workers and farmers who would not understand legislative jargon from government documents and publications. 


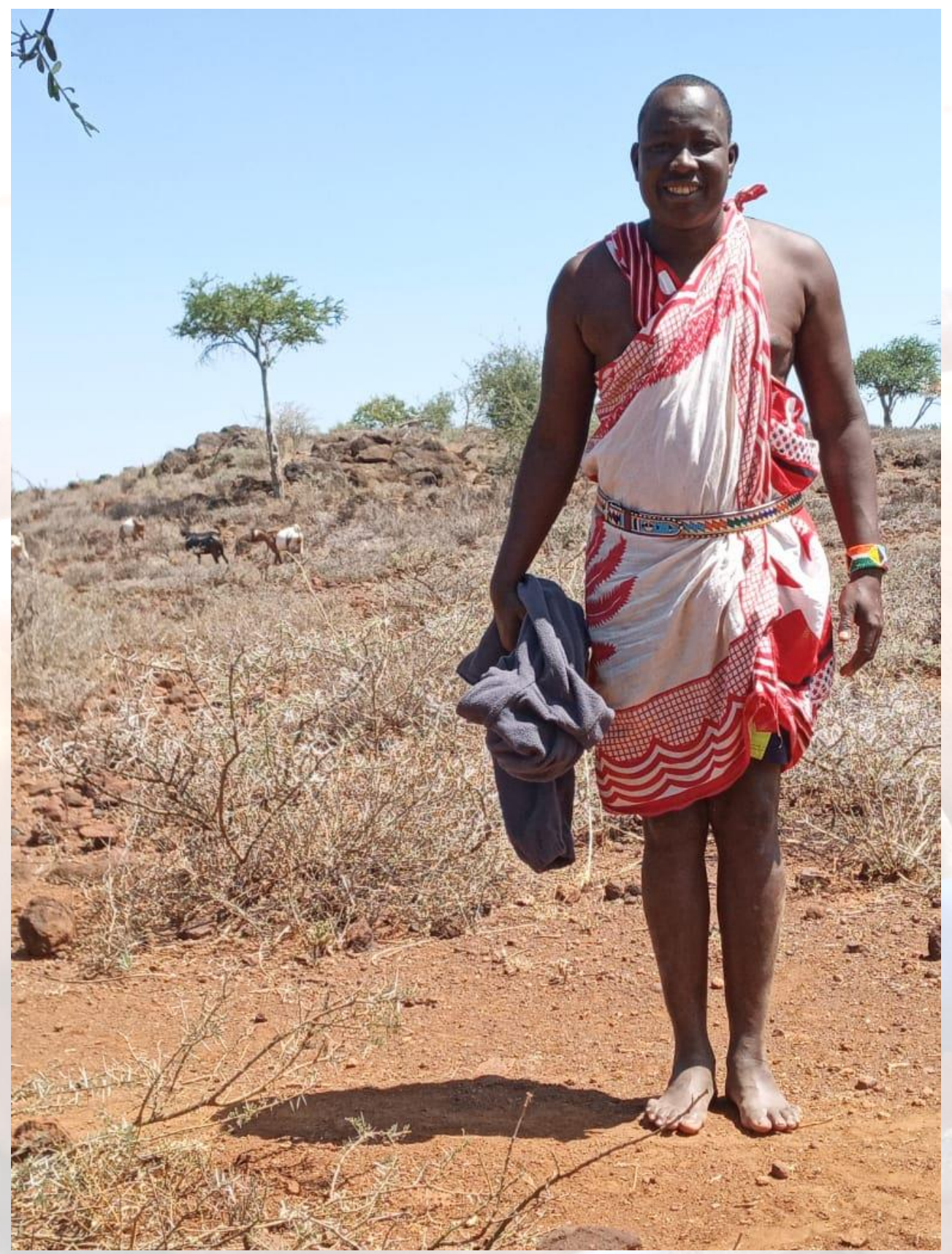

Figure 8: Farmer Komoi Ole Mukonyo at his farm in Ewuaso Oonkidong'i, Kajiado West, Kenya

It is apparent at the grass root level that government involvement is at a bare minimum and this is in agreement with the study done by 
Mogoa and colleagues which demonstrated that there is a lack of monitoring of animal cruelty incidences, reluctance to enforce legislation and non-existent training and awareness programmes to educate the community on matters concerning animal welfare (Mogoa et al., 2007).

This memo has:

- Highlighted the major animal welfare concerns in Kenya and it is our hope that front-line workers will learn to keep vigilant on these matters.

- Summarized the laws and what farmers and other front line workers should know and understand in an easy language thus educating them to be better law-abiding citizens.

- Mentioned various self-help groups and cooperative societies that farmers can join or approach and donors can work with to provide funding for agricultural activities which may lead to favorable outcomes. It is of great benefit to front-line workers that this memo also mentions various sources of funding that they can look into incase of financial constraints. 
Upholding animal welfare secures the livelihood of farmers and other stakeholders. We hope that publication of these findings will initiate a dialogue from both a local and global perspective concerning the level of involvement of front-line workers shedding more light into their involvement and what can be improved.

The work provided a rare opportunity to go into the field and sensitize various communities on the importance of animal welfare, creating a conscious vigilance when it comes to detecting and witnessing animal abuse.

Hopefully these findings will influence government policies concerning animal welfare in Kenya by providing recommendations from an informed perspective ensuring introduction of novel sustainable practices that allow farmers to work together with government parastatals to monitor animal handling, health and general living conditions thus improving animal welfare. 


\subsection{Recommendations of Practical Solutions \& Future Outlook}

- Future work should focus on evaluating the state of animal welfare in other regions that were excluded from this study and perhaps inclusion of animals kept for research purposes and wildlife as well. This will ensure in-depth findings that will influence development of policies that encourage the application of the 3Rs principles by Burch \& Russel, 1959 even further contributing towards anti-poaching efforts.

- In addition, comprehensive programmes targeting farmers and other non-academic front-line workers of the farming industry should be implemented to foster a deeper understanding of government regulations concerning animal welfare.

- Programmes should also be introduced to influence the generation of strong policies that promote animal welfare and eliminate animal cruelty through engagement of relevant advocates and policymakers who are in critical positions to foster the required changes. 


\subsection{Where should front-line workers report incidences or suspected cases of animal cruelty?}

The previously mentioned Constitution of Kenya Act No: CAP. 360 Part II Section 30 states that front-line workers and other members of the public can report matters concerning animal cruelty/ abuse to the police, chief or any other authorized leaders in the community.

In addition to that the Kenya Society for the Protection \& Care of Animals (KSPCA) has provided their contact information i.e. Email: info@kspca-kenya.org and Telephone number: 0202430318 / $0798303940 / 0733571125$ as an alternative option for reporting of suspected animal cruelty cases. KSPCA has offices and representatives in all major cities and towns in Kenya. 


\subsection{REFERENCES}

1. Alarcon, P., et al., Urban Livestock Keeping in the City of Nairobi: Diversity of Production Systems, Supply Chains, and Their Disease Management and Risks. Frontiers in Veterinary Science, 2017. 4: p. 171

2. Bankman, J. \& Muriithi, J. 2021. Engaging academics in efforts to counter the growth of factory farming in Africa. Brighter green Project Report

3. Broom, D. 1991. Animal Welfare: Concepts and Measurements. Journal of Animal Science, 69: 4167-4175.

4. Edwards-Callaway, L.N. and M.S. Calvo-Lorenzo, Animal Welfare in the US slaughter industry-a focus on fed cattle. Journal of Animal Science, 2020. 98(4).

5. Greger, M., 2007. The long haul: risks associated with livestock transport. Biosecurity \& Bioterrorism: Biodefense strategy, practice \& science. 5 (4): DOI: 10.1089/bsp.2007.0028

6. Greger, M. 2011 . Transgenesis in animal agriculture and zoonotic disease resistance. CAB Reviews: Perspectives in Agriculture, Veterinary Science, Nutrition \& Natural Resources, 6, No. 041.

7. Greger, M. \& Koneswaran, G. 2010. The public health impacts of concentrated animal feeding operations on local communities. Fam Community Health, 33 (1): 373-382

8. Kimwele, C., D. Matheka and H. Ferdowsian, A Kenyan perspective on the use of animals in science education and scientific research in Africa and prospects for improvement. The Pan African Medical Journal, 201 1. 9: p. 45

9. Masiga, W. \& Munyua, S. 2005. Global Perspectives on animal welfare: Africa, Rev. sci. tech. Off. Int. Epiz, 24 (2), 579-586 
10. Manning, J., D. Power, and A. Cosby, Legal Complexities of Animal Welfare in Australia: Do On-Animal Sensors Offer a Future Option? Animals: an open access journal from MDPI, 2021. 11(1): p.91

11. Mogoa, E., Wabacha, J., Mbithi, P. \& Kiama, S. 2007. An Overview of Animal Welfare Issues in Kenya. The Kenya Veterinarian, 29: 48-52.

12. Molomo, M. \& Mumba, T. 2014. Drivers for animal welfare policies in Africa, Rev. sci. tech. Off. Int. Epiz, 33 (1), 47-53

13. Njisane, Y.Z., F.E. Mukumbo, and V. Muchenje, An outlook on livestock welfare conditions in African communities - A review. Asian-Australian journal of animal sciences, 2020. 33(6): p. 867-878.

14. Rioja-Lang, F.C., et al., Prioritization of Farm Animal Welfare Issues Using Expert Consensus. Frontiers in Veterinary Science, 2020. 6(495).

15. OIE - Terrestrial Animal Health Code. 2019. Section 7: Animal Welfare, Chapter 7.1: Introduction to the recommendations for animal welfare", 7.1.1-7.1.5

16. Thornton, P.K. Livestock production: recent trends, future prospects. Philosophical transactions of the Royal Society of London. Series B, Biological Sciences, 2010. 365(1554):p.2853-2867

17. Thumbi, S.M., et al., Linking Human Health and Livestock Health: A "OneHealth" Platform for Integrated Analysis of Human Health, Livestock Health, and Economic Welfare in Livestock Dependent Communities. PLOS ONE, 2015. 10(3): p.e0120761

18. Wambui, J., Lamuka, P., Karuri, E. \& Matofari, J. 2018. Animal Welfare Knowledge, Attitudes and Practices of Stockpersons in Kenya. Anthrozoos, 31 (4): 397-410.

C 2021 Tiny Beam Fund, Inc. All rights reserved.

This Guidance Memo was created under a fellowship award from Tiny Beam Fund, Inc. All statements, 